Research Article

\title{
Synthesis and Application of
}

Nanocrystalline-Cellulose-Supported Acid Ionic

Liquid Catalyst in Pechmann Reaction

\author{
Moslem Mansour Lakouraj, Nazanin Bagheri, and Vahid Hasantabar \\ Department of Organic Chemistry, Faculty of Chemistry, University of Mazandaran, Babolsar 47416, Iran \\ Correspondence should be addressed to Moslem Mansour Lakouraj; lakouraj@umz.ac.ir
}

Received 21 June 2013; Accepted 10 September 2013

Academic Editor: Jianjun Li

Copyright @ 2013 Moslem Mansour Lakouraj et al. This is an open access article distributed under the Creative Commons Attribution License, which permits unrestricted use, distribution, and reproduction in any medium, provided the original work is properly cited.

\begin{abstract}
Nanocrystalline-cellulose-supported acidic ionic liquid carrying $\mathrm{SO}_{3} \mathrm{H}$ functional group was prepared using nanocrystalline cellulose, imidazole and 1,4-butane sultone as the source chemicals. The prepared nanocrystalline-cellulose-supported ionic liquid catalyst was characterized by AFM and SEM and its catalytic activity in the reaction of resorcinol with ethyl acetoacetate was tested in a solvent-free condition. The effects of reaction time, reaction temperature, and the ratio of catalyst on the conversion of resorcinol were investigated. A variety of coumarin derivatives were obtained in good yield in the absence of solvent.
\end{abstract}

\section{Introduction}

Coumarins are very significant heterocyclic compounds in organic synthesis. These compounds are known as benzo2-pyrone derivatives which are principally found in plants. Most of coumarin derivatives show some useful bioactivities. These compounds are widely used for pharmaceutical and agricultural applications and fragrance [1]. The Pechmann reaction is one of the most valuable methods for synthesis of coumarin which starts by phenols and acidic catalysts like concentrated sulfuric acid and Bronsted acidic ionic liquid [2]. Moreover, some other harsh catalysts used in the Pechmann reaction are $\mathrm{InCl}_{3}, \mathrm{ZrCl}_{4}, \mathrm{Yb}(\mathrm{OTF})_{3}$, and pTSOH [3]. These methods have some disadvantages such as by-products formation, long reaction time, and corrosion problems. So, there have been some attempts to find optional and safe synthetic routes [4]. However, most of these methods also suffer from problematic conditions such as expensive reagent, durable workup, large amount of support, or a catalyst which makes large amount of toxic waste. Therefore, with considering these problems, we tried to introduce a new ecofriendly catalyst to promote the Pechmann reaction.
Obviously, heterogeneous catalysts such as solid phase supported catalysts are particularly attractive for synthesis of chemical compounds because they allow simple separation of catalyst from the reaction mixture and prevent the release of toxic material to the environment. In recent years science of catalysts is shifting to reusable resources and ecofriendly processes. Thus, biodegradable and biocompatible polymers are appropriate alternatives in serving on the catalytic field $[5,6]$.

Among the biopolymers, cellulose and its derivatives are extensively used in chemicals and bioapplications. They are also applied as support for synthesis of organic compounds because cellulose and its derivatives are biodegradable, environmentally safe, widely abundant in nature, and easy to handle.

On the other hand, because of the unique physical and chemical properties of nanoscale materials especially in catalytic reactions, synthesis and application of nanostructured materials are an important field in nanoscience and technology. Through these, nanocrystalline cellulose (NCC) has attracted a great deal of interest in the nanocomposite field due to its intensive properties such as nanosize dimension, high surface area, and unique morphology [7]. Extensive 
researches have showed that NCC can be used for many application such as pharmaceutical, optical, and nanocomposite materials [8-10].

Therefore, in this project, we have prepared and applied nanocrystalline-cellulose-supported sulfonic acid ionic liquid as a highly efficient catalyst in promotion of the Pechmann reaction for convenient synthesis of coumarins in solvent free conditions.

\section{Materials and Methods}

Chemicals were purchased from Merck and Fluka chemical companies. ${ }^{1} \mathrm{H}$ NMR and ${ }^{13} \mathrm{C}$ NMR spectra were recorded on Bruker Avance DRX $400 \mathrm{MHz}$ spectrometer. IR spectra were recorded on a Bruker FTIR spectrometer. Melting points were measured on an Electrothermal 9100 apparatus. Characterization of cellulose whiskers was performed using scanning electron microscopy (SEM) (XL30, Philips, the Netherlands) at $30 \mathrm{kV}$ and atomic force microscopy (AFM) Nanosurf Easy Scan 2 Flex AFM (tapping mode).

2.1. Preparation of Nanocrystalline Cellulose (NCC). NCC suspension was produced according to the already reported procedure with slight modification [11]. Microcrystalline cellulose powder $(1.0 \mathrm{~g})$ was hydrolyzed by sulfuric acid $(8.75 \mathrm{~mL}, 64 \% \mathrm{w} / \mathrm{v})$ for $4 \mathrm{~h}$ at $50^{\circ} \mathrm{C}$ with continuous stirring. The hydrolysis was quenched by adding an excess amount of distilled water $(50 \mathrm{~mL})$ to the reaction mixture. The resulting mixture was centrifuged at $3,500 \mathrm{rpm}$ for $30 \mathrm{~min}$. After decanting, water $(50 \mathrm{~mL})$ was added to the precipitate and the mixture was then sonicated for $5 \mathrm{~min}$ to form a new suspension. This centrifugation/sonication process was repeated six times.

2.2. Preparation of Catalyst Glycidyl Ether of the Nanocrystalline Cellulose. In a round-bottom flask equipped with condenser, $1 \mathrm{~N} \mathrm{NaOH}(2 \mathrm{~mL})$ was added to a suspension of prepared NCC $(2 \mathrm{~g})$. The system was homogenized for 10 min on an ice bath $\left(T \leq 5^{\circ} \mathrm{C}\right)$. For the synthesis of epoxidized nanocrystalline cellulose, the excess amount of epichlorohydrin $(6 \mathrm{~mL})$ was added in stepwise manner and homogenization continued for another $15 \mathrm{~min}$. The obtained milky solution was then heated gradually to $60-65^{\circ} \mathrm{C}$ for $2.5 \mathrm{~h}$. The mixture was then neutralized with distilled water and washed twice with $10 \mathrm{~mL}$ of a solution of acetone : water $(85: 15)$ and finally twice more with $20 \mathrm{~mL}$ of acetone. The resulting solid was separated by simple filtration and dried overnight at room temperature.

$$
\text { IR (KBr): 989, 1060, 2881, 2995, } 3388 \mathrm{~cm}^{-1} \text {. }
$$

\subsection{Ring Opening of Epoxidized Nanocrystalline Cellulose} with Imidazole. A mixture of imidazole $(0.34 \mathrm{~g})$, epoxidized nanocrystalline cellulose $(0.9 \mathrm{~g})$, and THF $(2 \mathrm{~mL})$ was placed in a round-bottom flask and stirred magnetically for $12 \mathrm{~h}$ at $60^{\circ} \mathrm{C}$. The resulting mixture was separated by simple filtration and washed with THF which afforded $1.2 \mathrm{~g}$ of imidazole functionalized NCC.

IR (KBr): 1100, 1160, 1370, 1634, 2920, $3352 \mathrm{~cm}^{-1}$.

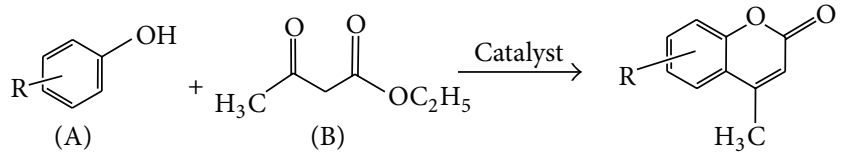

Scheme 1: The Pechmann reaction.

Elemental analysis: found; C (41.91\%), H (4.45\%), N (10.47\%); calculated (based on monofunctionalized glucopyranose repeating units of cellulose); C (59.87\%), H (6.4\%), N (17.46\%).

2.4. Synthesis of NCC-Supported Ionic Liquid. $\mathrm{SO}_{3} \mathrm{H}$-functionalized Bronsted acidic ionic liquid was prepared in the laboratory according to the procedure outlined in the literature $[12,13]$. In a typical preparation procedure, the imidazole functionalized NCC $(0.5 \mathrm{~g})$ was mixed with $1,4-$ butane sultone $(0.31 \mathrm{~g})$ while being stirred at $40^{\circ} \mathrm{C}$ for $12 \mathrm{~h}$. After completion, the zwitterions mass was washed three times with diethyl ether and then dried under vacuum $\left(120^{\circ} \mathrm{C}\right.$, 0.01 Torr). A stoichiometric amount of sulfuric acid was then added to the zwitterionic precipitate. The mixture was stirred at $50^{\circ} \mathrm{C}$ for $8 \mathrm{~h}$ to obtain the supported ionic liquid. The structures of the prepared supported ionic liquid are shown in Scheme 1.

IR (KBr): 1040, 1180, 1349, 1450, 1632, 2900, $3320 \mathrm{~cm}^{-1}$.

2.5. Typical Procedure for Synthesis of Coumarins. In a typical experiment, nanocrystalline-cellulose-supported acidic ionic liquid which was prepared based on some literature (Scheme 1) [11-13] (0.02 g) was mixed in a mixture of resorcinol $(1.5 \mathrm{mmol})$ and ethyl acetoacetate $(1.5 \mathrm{mmol})$ in a $25 \mathrm{~mL}$ round-bottom flask equipped with a distillation condenser. The content was stirred vigorously for the desired time at $80^{\circ} \mathrm{C}$. The reaction progress was monitored by TLC using n-hexane : ethyl acetate, $3: 1$, as eluent. On completion, the reaction mixture was cooled to room temperature. The liquid mixture solidified at ambient temperature. Ethanol $(10 \mathrm{~mL})$ was added and heated at $50^{\circ} \mathrm{C}$ until complete dissolution of the solid. Then the mixture was filtered to separate the catalyst. The solution was poured in a $100 \mathrm{~mL}$ beaker containing a lot of water. Crystalline product was collected by filtration to give 7-hydroxy-4-methylcoumarin in $95 \%$ yield. The crude crystal was recrystallized from EtOH to give pure 7-hydroxy-4-methylcoumarin [14].

\subsection{Spectral Data for Coumarins}

Entry 1: ${ }^{1} \mathrm{H}$ NMR $\left(400 \mathrm{MHz}, \mathrm{CDCl}_{3}\right): \delta 2.42(\mathrm{~d}, 3 \mathrm{H}), 6.32(\mathrm{q}$, $1 \mathrm{H}), 7.15-7.42(\mathrm{~m}, 3 \mathrm{H}), 7.48(\mathrm{~d}, J=6.0 \mathrm{~Hz}, 1 \mathrm{H})$.

${ }^{13} \mathrm{C}$ NMR $\left(100 \mathrm{MHz}, \mathrm{CDCl}_{3}\right): \delta 19.1,116,117.9,122,124.1$, 124.6, 132.6, 153, 154.5, 161.6. IR (KBr): 1064, 1238, 1543, 1705, $3020 \mathrm{~cm}^{-1}$.

Entry $2:{ }^{1} \mathrm{H}$ NMR $\left(400 \mathrm{MHz}, \mathrm{CDCl}_{3}\right): \delta 2.35(\mathrm{~d}, 3 \mathrm{H}), 6.11(\mathrm{q}$, $1 \mathrm{H}), 6.69(\mathrm{~d}, J=2.4 \mathrm{~Hz}, 1 \mathrm{H}), 6.78(\mathrm{dd}, J=8.8 \mathrm{~Hz}, 1 \mathrm{H}), 7.56(\mathrm{~d}$, $J=8.8 \mathrm{~Hz}, 1 \mathrm{H}), 10.52(\mathrm{~s}, 1 \mathrm{H})$. 
${ }^{13} \mathrm{C} \mathrm{NMR}\left(100 \mathrm{MHz}, \mathrm{CDCl}_{3}\right): \delta 18.56,102.62,110.70$, $112.47,113.29,127.05,153.97,155.28,160.74,161.60$.

IR (KBr): 1060, 1225, 1590, 1680, $3100 \mathrm{~cm}^{-1}$.

Entry 3: ${ }^{1} \mathrm{H}$ NMR (400 MHz, $\left.\mathrm{CDCl}_{3}\right): \delta 2.42(\mathrm{~d}, 3 \mathrm{H}), 6.33(\mathrm{q}$, $1 \mathrm{H}), 6.73(\mathrm{~d}, J=8.4 \mathrm{~Hz}, 1 \mathrm{H}), 6.81(\mathrm{~d}, J=8.4 \mathrm{~Hz}, 1 \mathrm{H}), 7.28$ (s, $1 \mathrm{H})$.

${ }^{13} \mathrm{C} \mathrm{NMR}\left(100 \mathrm{MHz}, \mathrm{CDCl}_{3}\right): \delta 18.38,109.40,114.40$, $117.50,120.65,121.54,147.10,153.93,155.10,159.70$.

IR (KBr): 1055, 1225, 1565, 1693, 3010, $3412 \mathrm{~cm}^{-1}$.

Entry 4: ${ }^{1} \mathrm{H}$ NMR $\left(400 \mathrm{MHz}, \mathrm{CDCl}_{3}\right): \delta 2.10(\mathrm{~s}, 3 \mathrm{H}), 2.31$ (d, $3 \mathrm{H}), 4.17$ (s, 1H), 6.71-7.29 (m, 3H).

${ }^{13} \mathrm{C} \mathrm{NMR}\left(100 \mathrm{MHz}, \mathrm{CDCl}_{3}\right): \delta 18.04,24.17,110.70,117.43$, $118.20,124.10,126.50,144.50,152.74,153.92,162.10$.

IR (KBr): 1070, 1146, 1212, 1248, 1378, 1579, 1636, 1704, $2920,2970 \mathrm{~cm}^{-1}$.

Entry 5: ${ }^{1} \mathrm{H}$ NMR (400 MHz, DMSO): $\delta 2.40$ (d, 3H), $3.86(\mathrm{~s}$, $3 \mathrm{H}), 6.21(\mathrm{q}, 1 \mathrm{H}), 6.95(\mathrm{~d}, 1 \mathrm{H}), 6.98(\mathrm{q}, 1 \mathrm{H}), 7.68(\mathrm{~d}, J=8.4 \mathrm{~Hz}$, $1 \mathrm{H})$.

${ }^{13} \mathrm{C}$ NMR (100 MHz, DMSO): $\delta 18.60,56.37,101.17,111.58$, $112.58,113.57,126.93,153.93,155.24,160.63,162.84$.

IR (KBr): 1068, 1284, 1510, 1725, 2927, $3070 \mathrm{~cm}^{-1}$.

Entry 6: ${ }^{1} \mathrm{H}$ NMR $\left(400 \mathrm{MHz}, \mathrm{CDCl}_{3}\right): \delta 2.34(\mathrm{~d}, 3 \mathrm{H}), 6.13(\mathrm{q}$, $1 \mathrm{H}), 6.63(\mathrm{~s}, 1 \mathrm{H}), 6.65(\mathrm{~d}, J=8.7 \mathrm{~Hz}, 1 \mathrm{H}), 7.50(\mathrm{~d}, J=8.7 \mathrm{~Hz}$, $1 \mathrm{H})$.

${ }^{13} \mathrm{C} \mathrm{NMR}\left(100 \mathrm{MHz}, \mathrm{CDCl}_{3}\right): \delta 19.40,101.57,109.40$, $111.58,114.57,123.46,153.17,154.41,154.63,162.84$.

IR (KBr): 1052, 1238, 1570, 1688, 3012, 3312, $3468 \mathrm{~cm}^{-1}$.

Entry 7: ${ }^{1} \mathrm{H}$ NMR (400 MHz, DMSO): $\delta 2.35$ (d, 3H), 6.12 (q, $1 \mathrm{H}), 6.80(\mathrm{~d}, J=8.4 \mathrm{~Hz}, 1 \mathrm{H}), 7.08(\mathrm{~d}, J=8.8 \mathrm{~Hz}, 1 \mathrm{H}), 9.67(\mathrm{~s}$, $1 \mathrm{H}), 10.04(\mathrm{~s}, 1 \mathrm{H})$.

${ }^{13} \mathrm{C}$ NMR $(100 \mathrm{MHz}, \mathrm{DMSO}): \delta 18.72,110.64,112.56$, $113.21,115.95,132.61,143.74,149.87,154.41,160.68$.

IR (KBr): 629, 807, 1006, 1064, 1186, 1337, 1480, 1524, 1653, $2925,3217 \mathrm{~cm}^{-1}$

Entry 8: ${ }^{1} \mathrm{H}$ NMR (400 MHz, DMSO): $\delta 2.53(\mathrm{~d}, 3 \mathrm{H}), 6.50(\mathrm{q}$, $1 \mathrm{H}), 7.68-7.74(\mathrm{~m}, 2 \mathrm{H}), 7.78(\mathrm{~d}, J=8.8 \mathrm{~Hz}, 1 \mathrm{H}), 7.87(\mathrm{~d}, J=$ $8.8 \mathrm{~Hz}, 1 \mathrm{H}), 8.02-8.06(\mathrm{~m}, 1 \mathrm{H}), 8.34-8.37(\mathrm{~m}, 1 \mathrm{H})$.

${ }^{13}$ C NMR (100 MHz, DMSO): $\delta 19.14,114.34,115.58,121.74$, $122.10,122.66,124.44,127.86,128.44,129.12,134.83,150.13$, $154.70,160.13$.

IR (KBr) 1044, 1275, 1572, 1750, 2922, $3012 \mathrm{~cm}^{-1}$.

Entry 9: ${ }^{1} \mathrm{H}$ NMR (400 MHz, $\mathrm{CDCl}_{3}$ ): $\delta 2.45$ (d, 3H), 6.32 (q, $1 \mathrm{H}), 7.32-7.60(\mathrm{~m}, 4 \mathrm{H}), 7.9(\mathrm{~d}, J=9.0 \mathrm{~Hz}, 1 \mathrm{H}), 8.54(\mathrm{~d}, J=$ $9.0 \mathrm{~Hz}, 1 \mathrm{H})$.

${ }^{13} \mathrm{C}$ NMR $\left(100 \mathrm{MHz}, \mathrm{CDCl}_{3}\right): \delta 24.40,109.47,115.70$, $117.76,123.60,126.35,126.53,128.91,129.84,134.58,153.40$, $154.90,160.30$

IR (KBr) 1044, 1215, 1514, 1630, $3052 \mathrm{~cm}^{-1}$.

Entry 11: ${ }^{1} \mathrm{H}$ NMR (400 MHz, DMSO): $\delta 2.46$ (d, 3H), $3.83(\mathrm{~s}$, $3 \mathrm{H}), 3.84(\mathrm{~s}, 3 \mathrm{H}), 5.98(\mathrm{q}, J=1.2 \mathrm{~Hz}, 1 \mathrm{H}), 6.46(\mathrm{~d}, J=2.4 \mathrm{~Hz}$, $1 \mathrm{H}), 6.54(\mathrm{~d}, J=2.4 \mathrm{~Hz}, 1 \mathrm{H})$.

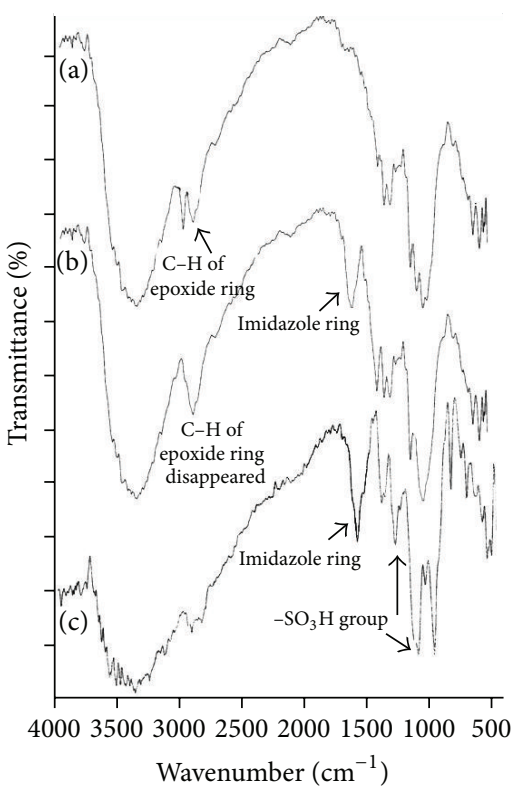

FIGURE 1: (a) Epoxidized NCC, (b) imidazole-NCC, and (c) NCCsupported ionic liquid.

${ }^{13} \mathrm{C}$ NMR (100 MHz, DMSO): $\delta$ 24.05, 56.31, 56.65, 94.01, 95.99, 104.35, 111.08, 154.63, 156.79, 159.43, 160.15, 163.14 .

IR $(\mathrm{KBr}): 1130,1353,1460,1616,1733,2939,2992$, $3024 \mathrm{~cm}^{-1}$.

\section{Results and Discussion}

Fourier transform infrared spectroscopy (FT-IR) is a useful technique for studying polysaccharides chemistry. Therefore, FT-IR analysis was performed to investigate the functionalization reaction. The spectrum of cellulose is well known in the literature which shows the characteristic vibrational bands including strong broad $\mathrm{OH}$ stretching (3300-4000 $\left.\mathrm{cm}^{-1}\right), \mathrm{C}-\mathrm{H}$ stretching of methine and methylene groups $\left(2800-3000 \mathrm{~cm}^{-1}\right)$, and the alcoholic $\mathrm{C}-\mathrm{O}$ and glycosidic bond vibrations around $1100-1150 \mathrm{~cm}^{-1}[19,20]$.

As seen in Figure 1, the spectra of both functionalized NCC showed the $\mathrm{C}-\mathrm{C}$ ring breathing band at $\sim 1040-1100 \mathrm{~cm}^{-1}$ and the C-O-C glycosidic ether band at $\sim 1150 \mathrm{~cm}^{-1}$ which arose from the cellulose segment. The presence of the stretching vibrations at $\sim 2800$ and $2900 \mathrm{~cm}^{-1}$ also indicated the methine and methylene content of the substituted NCC. No noticeable differences were observed between the spectra of epoxidized cellulose (as seen in Figure 1(a)) and that of original cellulose, demonstrating that the glucopyranoside rings were preserved during the functionalization reaction.

Comparison of IR spectra of imidazole-containing NCC (Figure 1(b)) with that of epoxidized NCC (Figure 1(a)) basically revealed that the vibrational frequency at $2995 \mathrm{~cm}^{-1}$ corresponding to the $\mathrm{C}-\mathrm{H}$ of the epoxide ring disappeared and new submerged bands were appeared about 1510 and $1634 \mathrm{~cm}^{-1}$ (aromatic skeletal stretching and $\mathrm{N}-\mathrm{H}$ bending 


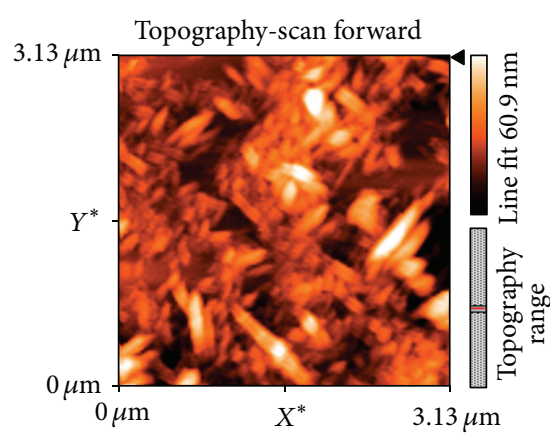

(a)

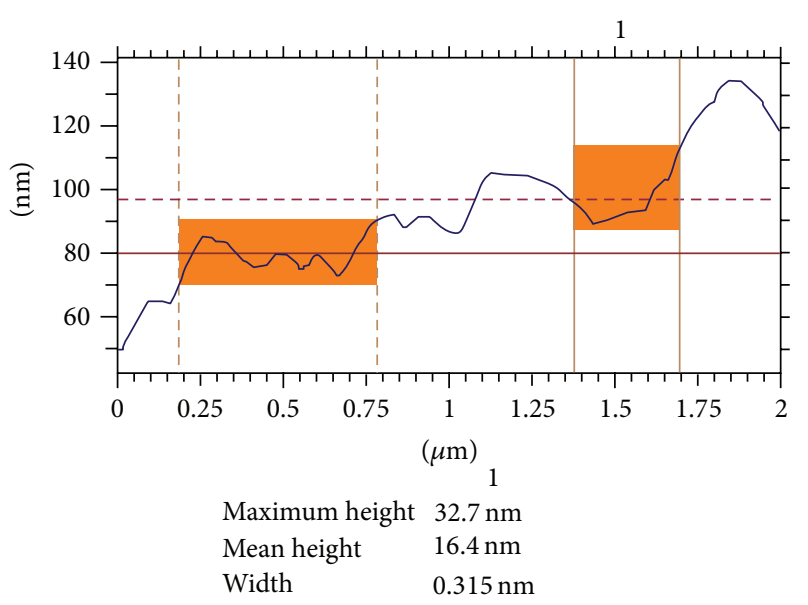

(b)

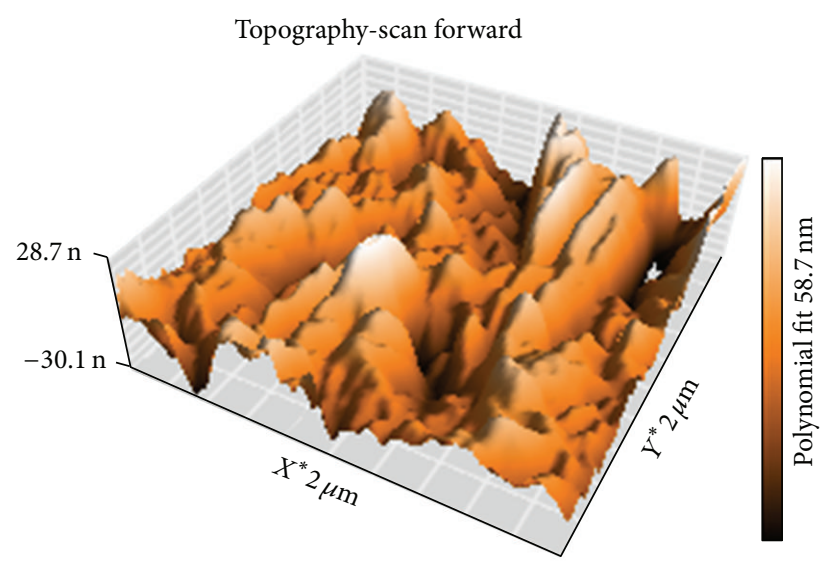

(c)

FIGURE 2: Atomic force microscope (AFM) image of NCC.

vibrations) and $1050-1200 \mathrm{~cm}^{-1}$ corresponding to $\mathrm{C}-\mathrm{N}$ vibrations.

In Figure 1(c), a strong vibrational band at $1349 \mathrm{~cm}^{-1}$ and a sharp peak at $1180 \mathrm{~cm}^{-1}$ together with a strong broad band of the acid functionality around $2500-3500 \mathrm{~cm}^{-1}$ approved the presence of sulfonic acid group on the catalyst. Summing up, these observations confirmed the successful formation of the functionalized sulfonic acid supported by NCC.

Characterization of cellulose nanocrystals was also performed using scanning electron microscopy (SEM) and atomic force microscopy (AFM). The size distribution of the cellulose nanocrystals was determined by AFM. It has been widely used to provide valuable and rapid indication of surface topography of NCC under ambient conditions.

Figures 2(a)-2(c) show the AFM which was obtained from dilute suspension of the cellulose nanocrystals. According to the AFM images, Figure 2(b) shows that the average and maximum height of NCC maintained diameters less than $50 \mathrm{~nm}$.

Morphology of this nanocomposite was studied with a scanning electron microscope (SEM). A representative SEM image of the cellulose-nanocrystals-supported ionic liquid is shown in Figure 3. It was clearly observed that the composite was in nanodimension size (about $48 \mathrm{~nm}$ ).

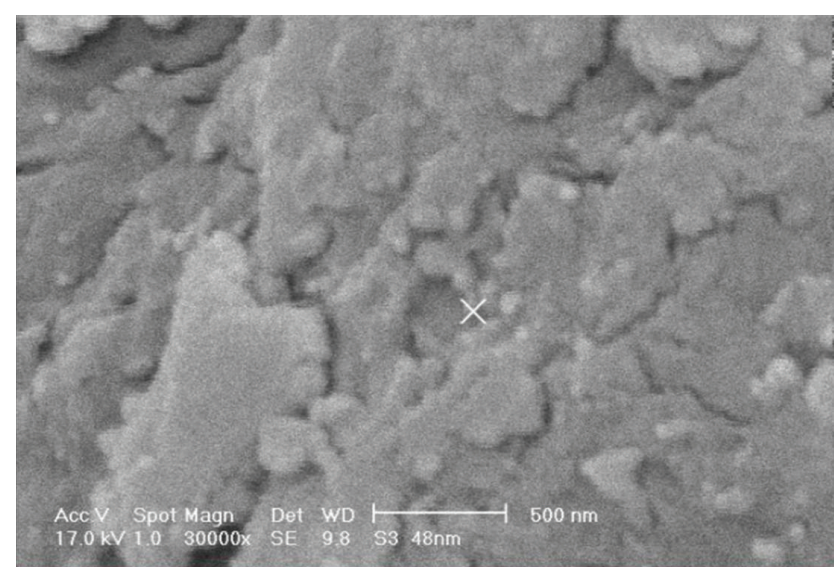

FIGURE 3: Scanning electron microscopy (SEM) of nanocrystallinecellulose-supported ionic liquid.

Chemically, coumarins can be synthesized by a range of methods such as the Perkin, Pechmann reaction, Knoevenagel condensation, Reformatsky, Wittig, and catalytic cyclization reactions [21-29]. Acid catalyzed Pechmann reaction is the simple and normally used method for synthesizing 


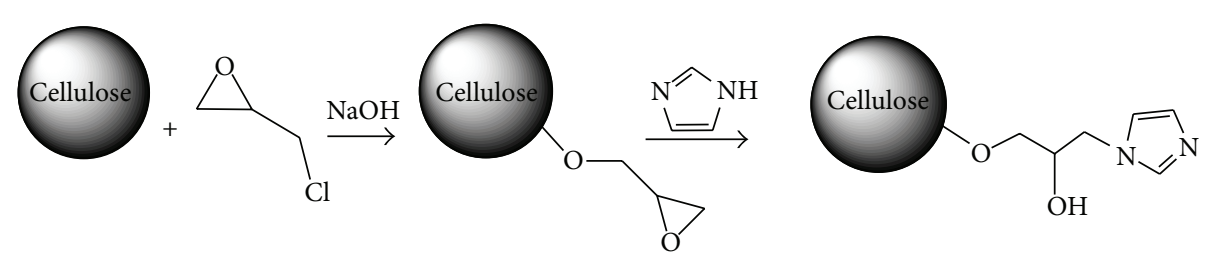

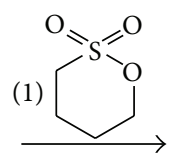

(2) $\mathrm{H}_{2} \mathrm{SO}_{4}$

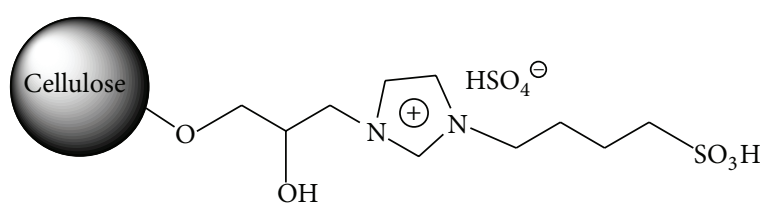

Scheme 2: Preparation of catalyst.

coumarins from activated phenols, mainly metasubstituted phenols containing nucleophilic substituent at meta-position.

We herein report an ecofriendly, facile, and efficient methodology for the synthesis of 4-methyl-2H-chromen-2ones using a nanosized acidic catalyst. This method involves the convenient synthesis of substituted coumarins by treatment of ethyl acetoacetate and substituted phenol using NCC supported sulfonic acid ionic liquid as an environmentally safe and efficient nanocomposite in catalytic amount to promote the reaction under solvent-free condition at $80^{\circ} \mathrm{C}$ (Scheme 2).

To establish the optimum condition on this reaction, first of all, various amounts of catalyst were examined using ethyl acetoacetate and resorcinol as model compounds. The effect of ratio of catalyst on resorcinol conversion and product selectivity was studied at $80^{\circ} \mathrm{C}$ using 5 to $20 \%$ of the catalyst while keeping the ethyl acetoacetate/resorcinol molar ratio at $1: 1$ (Table 1).

The excellent yield was obtained with $10 \%$ of the catalyst. Next, to find the best solvent, the reaction of ethylacetoacetate and resorcinol using $10 \%$ of catalyst was monitored at $80^{\circ} \mathrm{C}$ in different solvents, namely, n-Hexane, THF, $\mathrm{CH}_{2} \mathrm{Cl}_{2}$, and $\mathrm{CH}_{3} \mathrm{CN}$, and also in solvent-free condition. The results are summarized in Table 2.

It was found that solvent-free condition stands out as the choice, with its fast conversion, high yield, and no side product, such as chromones formation [30,31].

And finally the influence of reaction temperature on conversion of resorcinol was investigated. The reaction was studied at various temperatures from room temperature up to $100^{\circ} \mathrm{C}$ and the results were summarized in Table 3 for $1: 1$ molar ratio of resorcinol/ethyl acetoacetate. Upon increasing the reaction temperature, the conversion of resorcinol and yield of coumarin increased rapidly and reached an equilibrium level up to $80^{\circ} \mathrm{C}$ and remained almost constant thereafter.

Using optimized reaction parameters, a variety of 4methyl-2H-chromen-2-ones were synthesized from ethyl acetoacetate and corresponding phenols (Table 4). In summary, a novel approach for the synthesis of 4-methyl-2Hchromen-2-ones has been explored by using nanocrystallinecellulose-supported sulfonic acid ionic liquid in solvent-free
TABle 1: Effect of catalyst ratio on Pechmann reaction.

\begin{tabular}{lccc}
\hline Entry & Catalyst $^{\mathrm{a}}$ & Time $(\mathrm{min})$ & Yield $^{\mathrm{b}}(\%)$ \\
\hline 1 & $5 \%$ & 37 & 90 \\
$\mathbf{2}$ & $\mathbf{1 0 \%}$ & $\mathbf{2 0}$ & $\mathbf{9 5}$ \\
3 & $15 \%$ & 12 & 90 \\
4 & $20 \%$ & 20 & 85 \\
\hline
\end{tabular}

${ }^{a}$ Weight percentage of catalyst. ${ }^{b}$ Yield refers to isolate products.

TABLE 2: Effect of solvent on condensation of ethyl acetoacetate with resorcinol.

\begin{tabular}{lccc}
\hline Entry & Solvent & Time (min) & Yield (\%) \\
\hline $\mathbf{1}$ & Solvent free & $\mathbf{2 0}$ & $\mathbf{9 5}$ \\
2 & $\mathrm{THF}$ & 30 & 90 \\
3 & $\mathrm{CH}_{3} \mathrm{CN}$ & 35 & 95 \\
4 & $\mathrm{CH}_{2} \mathrm{Cl}_{2}$ & 12 & 95 \\
5 & n-Hexane & 20 & 90 \\
\hline
\end{tabular}

TABLE 3: Effect of reaction temperature on resorcinol conversion.

\begin{tabular}{lccc}
\hline Entry & Temperature $\left({ }^{\circ} \mathrm{C}\right)$ & Time & Yield (\%) \\
\hline 1 & r.t & $24(\mathrm{~h})$ & 92 \\
2 & 50 & $5(\mathrm{~h})$ & 89 \\
3 & 70 & $35(\mathrm{~min})$ & 80 \\
$\mathbf{4}$ & $\mathbf{8 0}$ & $\mathbf{2 0}(\mathrm{min})$ & $\mathbf{9 5}$ \\
5 & 100 & $18(\mathrm{~min})$ & 80 \\
\hline
\end{tabular}

condition, which showed advantages leading to an effective and attractive process for the preparation of coumarins. Results showed that in the presence of stronger electron donating groups on phenolic reactants the rate and yield of reaction will be enhanced significantly due to the positive electronic effect of the substituents. In the case of $\beta$-naphthol (entry 9), the steric hindrance of hydrogen atom at 8position inhibits the cyclization reaction, while $\alpha$-naphthol reacts more easily to produce the corresponding coumarin (Scheme 3). 
TABLE 4: Preparation of coumarins using NCC-supported sulfonic acid ionic liquid ${ }^{\mathrm{a}}$.

\begin{tabular}{|c|c|c|c|c|c|c|}
\hline Entry & Reactant & Product & Time & Yield $(\%)^{b}$ & m.p $\left({ }^{\circ} \mathrm{C}\right)$ & Lit. $^{c}$ \\
\hline 1 & & $\mathrm{CH}_{3}$ & $24(\mathrm{~h})$ & trace & $77-79$ & 79-81 [15] \\
\hline 2 & & & $20(\min )$ & 95 & 185 & $182-184[14]$ \\
\hline 3 & & & $6.5(\mathrm{~h})$ & 60 & 244 & $241-242$ [15] \\
\hline 4 & & & $6(\mathrm{~h})$ & 20 & 130-132 & $130-131[16]$ \\
\hline 5 & & & $5(\mathrm{~h})$ & 80 & $161-162$ & $158-160$ [14] \\
\hline 6 & & & $1.5(\mathrm{~h})$ & 75 & $221-224$ & $220-224$ [17] \\
\hline 7 & & & $20(\min )$ & 85 & $230-233$ & $234-235$ [14] \\
\hline 8 & & & $5(\mathrm{~h})$ & 94 & 154-156 & $153-155[14]$ \\
\hline 9 & & & $10(\mathrm{~h})$ & 40 & $180-182$ & $182-183$ [18] \\
\hline
\end{tabular}


TABLE 4: Continued.

Entry Reactant

${ }^{a}$ The reactions were performed in the absence of solvent at $80^{\circ} \mathrm{C} .{ }^{b}$ Isolated yields. ${ }^{c}$ The products were characterized by comparison of their spectroscopic and physical data with reference samples synthesized by the reported procedure.

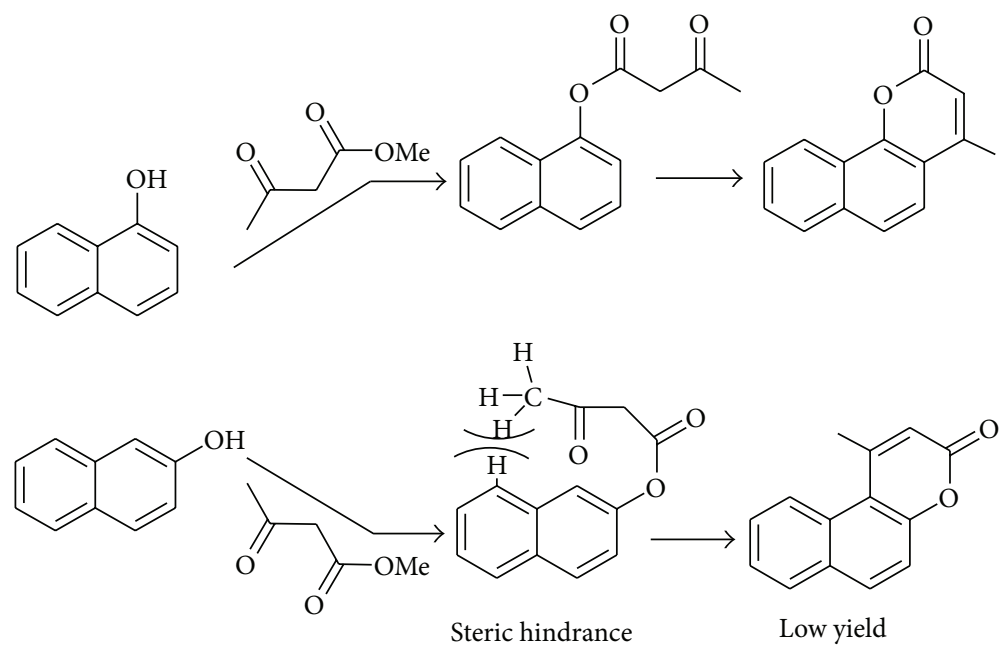

SCHEME 3: Proposed mechanistic pathway for naphthols.

\section{Conclusion}

The reaction condition is relatively mild and workup procedure is simple. The catalyst was separated by filtration and after washing with petroleum ether reused for the new experiments. The reaction conversion for the model reaction after 3 times recycling and reuse of the catalyst gradually reduced to $68 \%$. In conclusion, we have found that NCCsupported acidic ionic liquid is an efficient catalyst for solid phase synthesis of coumarins via the Pechmann reaction. The significant features of the method are (a) operation simplicity, (b) mild reaction condition, and (c) use of an environmentally benign and reusable catalyst.

\section{Acknowledgment}

The authors are grateful to the research councils of Mazandaran University for the financial support.

\section{References}

[1] M. A. Musa, A. Zhou, and O. A. Sadik, "Synthesis and antiproliferative activity of new coumarin-based benzopyranone derivatives against human tumor cell lines," Medicinal Chemistry, vol. 7, no. 2, pp. 112-120, 2011.

[2] E. C. Horning, Organic Synthesis, John Wiley \& Sons, New York, NY, USA, 1955.

[3] P. G. Mandhane, R. S. Joshi, A. R. Ghawalkar, G. R. Jadhav, and C. H. Gill, "Ammonium metavanadate: a mild and efficient catalyst for the synthesis of coumarins," Bulletin of the Korean Chemical Society, vol. 30, no. 12, pp. 2969-2972, 2009.

[4] M. C. Laufer, H. Hausmann, and W. F. Hçlderich, "Synthesis of 7-hydroxycoumarins by Pechmann reaction using Nafion resin/ silica nanocomposites as catalysts," Journal of Catalysis, vol. 218, no. 2, pp. 315-320, 2003.

[5] K. R. Reddy, N. S. Kumar, and B. Sreedhar, "N-Arylation of nitrogen heterocycles with aryl halides and arylboronic 
acids catalyzed by cellulose supported copper(0)," Journal of Molecular Catalysis A, vol. 252, no. 1-2, pp. 136-141, 2006.

[6] E. Guibal, "Heterogeneous catalysis on chitosan-based materials: a review," Progress in Polymer Science, vol. 30, no. 1, pp. 71109, 2005.

[7] R. M. Matos, J. Y. Cavaillé, A. Dufresne, J. F. Gérard, and C. Graillat, "Processing and characterization of new thermoset nanocomposites based on cellulose whiskers," Composite Interfaces, vol. 7, no. 2, pp. 117-131, 2000.

[8] K. Fleming, D. G. Gray, and S. Matthews, "Cellulose crystallites," Chemistry A, vol. 7, no. 9, pp. 1831-1836, 2001.

[9] J.-F. Revol, L. Godbout, and D. G. Gray, "Solid self-assembled films of cellulose with chiral nematic order and optically variable properties," Journal of Pulp and Paper Science, vol. 24, no. 5, pp. 146-149, 1998.

[10] S. Hill, "Cars that grow on trees," New Scientists, vol. 153, no. 2067, pp. 36-39, 1997.

[11] X. M. Dong, J.-F. Revol, and D. G. Gray, "Effect of microcrystallite preparation conditions on the formation of colloid crystals of cellulose," Cellulose, vol. 5, no. 1, pp. 19-32, 1998.

[12] J. Fraga-Dubreuil, K. Bourahla, M. Rahmouni, J. P. Bazureau, and J. Hamelin, "Catalysed esterifications in room temperature ionic liquids with acidic counteranion as recyclable reaction media," Catalysis Communications, vol. 3, no. 5, pp. 185-190, 2002.

[13] J. Gui, X. Cong, D. Liu, X. Zhang, and Z. Hu, "Novel Brønsted acidic ionic liquid as efficient and reusable catalyst system for esterification," Catalysis Communications, vol. 5, no. 9, pp. 473477,2004

[14] S. B. Patil, R. P. Bhat, V. P. Raje, and S. D. Samant, "Ultrasoundassisted Pechmann condensation of phenols with $\beta$-ketoesters to form coumarins, in the presence of bismuth(III) chloride catalyst," Synthetic Communications, vol. 36, no. 4, pp. 525-531, 2006.

[15] L. L. Woods and J. Sapp, "A new one-step synthesis of substituted coumarins," The Journal of Organic Chemistry, vol. 27, no. 10, pp. 3703-3705, 1962.

[16] A. Russel and J. R. Frye, "2,6-Dihydroxyacetophenone," Organic Syntheses, vol. 21, p. 22, 1941.

[17] R. L. Atkins and D. E. Bliss, "Substituted coumarins and azacoumarins. Synthesis and fluorescent properties," The Journal of Organic Chemistry, vol. 43, no. 10, pp. 1975-1980, 1978.

[18] A. S. R. Anjaneyulu, L. R. Row, C. S. Krishna, and C. Srinivasulu, "Synthesis of benzochromenes and related compounds," Current Science, vol. 37, p. 513, 1968.

[19] R. Bodirlau and C. A. Teaca, "Fourier transform infrared spectroscopy and thermal analysis of lignocellulose fillers treated with organic anhydrides," Romanian Journal of Physics, vol. 54, no. 1-2, pp. 93-104, 2009.

[20] C. Qi and Z. Dehe, "Grafting of humic acid onto cotton cellulose (II)," Chinese Journal of Polymer Science, vol. 6, no. 2, p. 165, 1988.

[21] B. J. Donnelly, D. M. Donnelly, and A. M. O. Sullivan, "Dalbergia species-VI : the occurrence of melannein in the genus dalbergia," Tetrahedron, vol. 24, no. 6, pp. 2617-2622, 1968.

[22] J. R. Johnson, "Other classical coumarins syntheses include the Perkin," Organic Reactions, vol. 1, pp. 210-285, 1942.

[23] Y. Gu, J. Zhang, Z. Duan, and Y. Denga, "Pechmann reaction in non-chloroaluminate acidic ionic liquids under solvent-free conditions," Advanced Synthesis \& Catalysis, vol. 347, no. 4, pp. 512-516, 2005.
[24] F. Bigi, L. C. hesini, R. Maggi, and G. Sartori, "Montmorillonite KSF as an inorganic, water stable, and reusable catalyst for the knoevenagel synthesis of coumarin-3-carboxylic acids," The Journal of Organic Chemistry, vol. 64, no. 3, pp. 1033-1035, 1999.

[25] R. L. Shriner, "Reformatsky Reaction," Organic Reactions, vol. 1, p. $15,1942$.

[26] N. S. Narasimhan, R. S. Mali, and M. V. Barve, "Synthetic application of lithiation peactions; part XIII. Synthesis of 3-phenylcoumarins and their benzo derivatives," Synthesis, vol. 1979, no. 11, pp. 906-909, 1979.

[27] I. Yavari, R. Hekmat-Shoar, and A. Zonousi, "A new and efficient route to 4-carboxymethylcoumarins mediated by vinyltriphenylphosphonium salt," Tetrahedron Letters, vol. 39, no. 16, pp. 2391-2392, 1998.

[28] N. Cairns, L. M. Harwood, and D. P. Astles, "Tandem thermal Claisen-cope rearrangements of coumarate derivatives. Total syntheses of the naturally occurring coumarins: suberosin, demethylsuberosin, ostruthin, balsamiferone and gravelliferone," Journal of the Chemical Society, Perkin Transactions, no. 21, pp. 3101-3107, 1994.

[29] M. R. Saidi and K. Bigdeli, "Microwave promoted and improved thermal synthesis of pyranocoumarins and furocoumarins," Journal of Chemical Research S, no. 12, pp. 800-801, 1998.

[30] A. Sinhamahapatra, N. Sutradhar, S. Pahari, H. C. Bajaj, and A. B. Panda, "Mesoporous zirconium phosphate: an efficient catalyst for the synthesis of coumarin derivatives through Pechmann condensation reaction," Applied Catalysis A, vol. 394, no. 1-2, pp. 93-100, 2011.

[31] S. Frere, V. Thieary, and T. Besson, "Microwave acceleration of the Pechmann reaction on graphite/montmorillonite K10: application to the preparation of 4-substituted 7-aminocoumarins," Tetrahedron Letters, vol. 42, no. 15, pp. 2791-2794, 2001. 

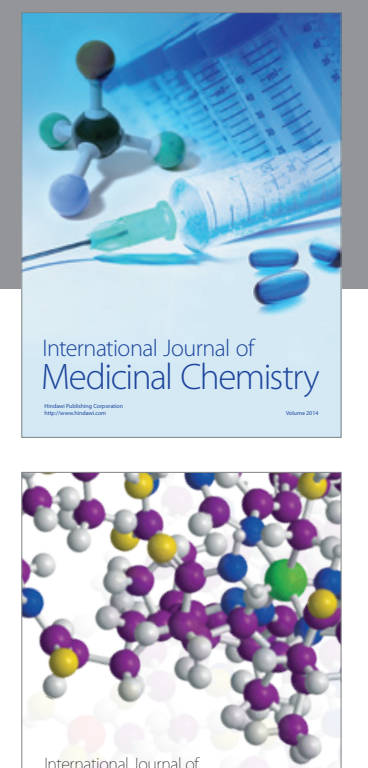

\section{Carbohydrate} Chemistry

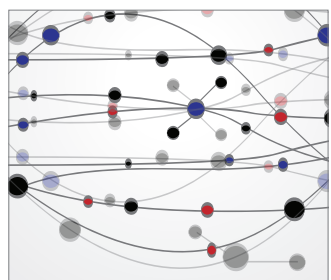

The Scientific World Journal
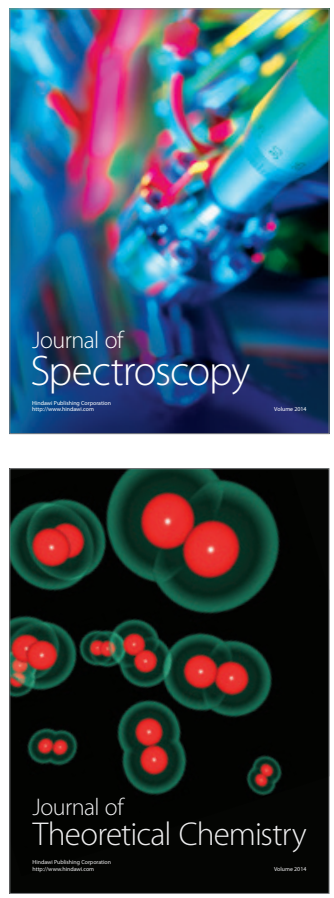
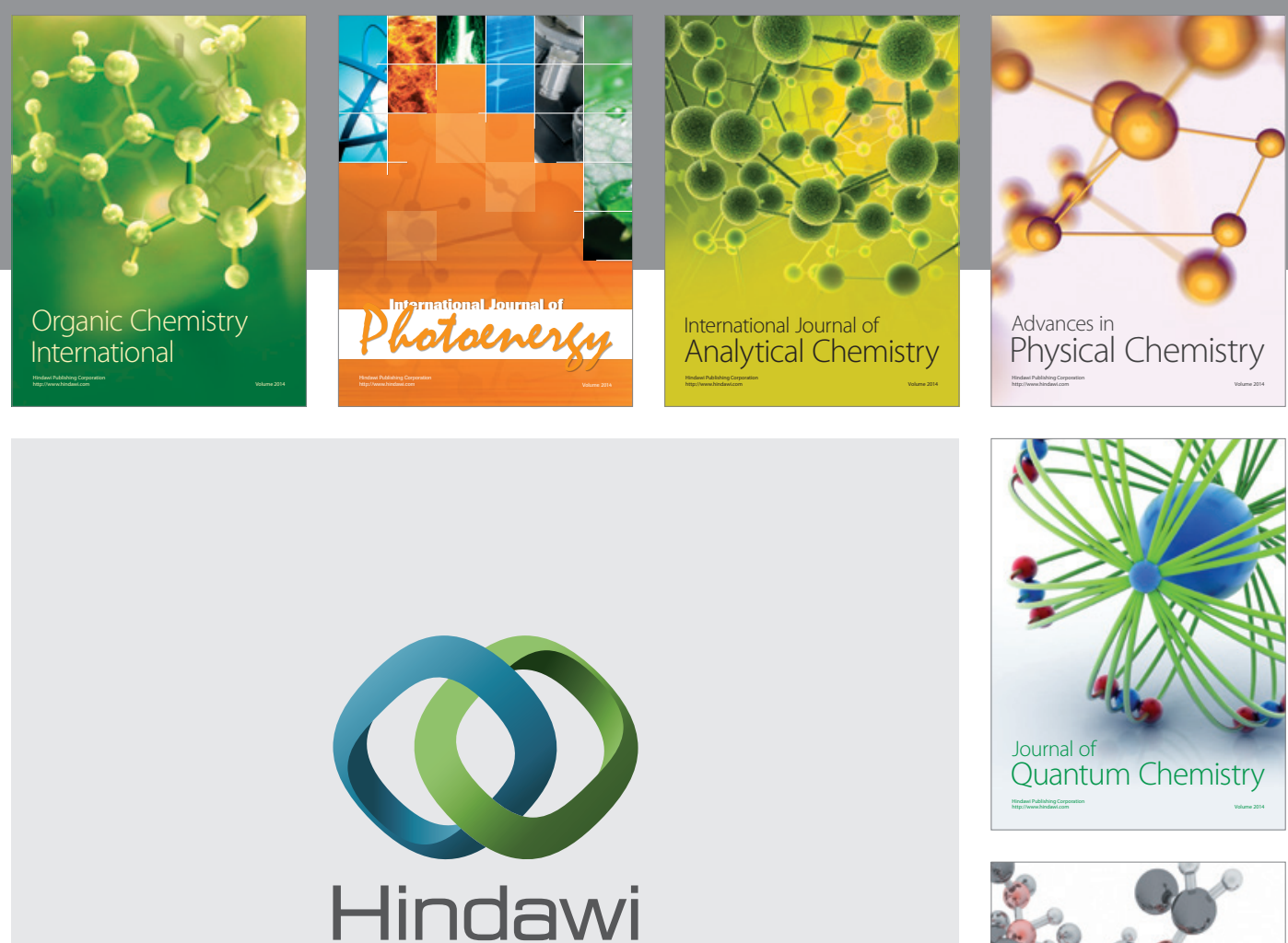

Submit your manuscripts at

http://www.hindawi.com

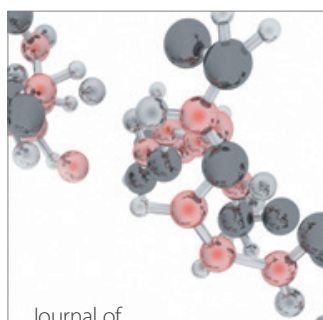

Analytical Methods

in Chemistry

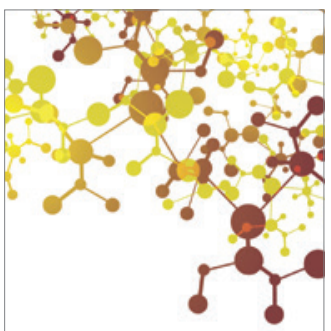

Journal of

Applied Chemistry

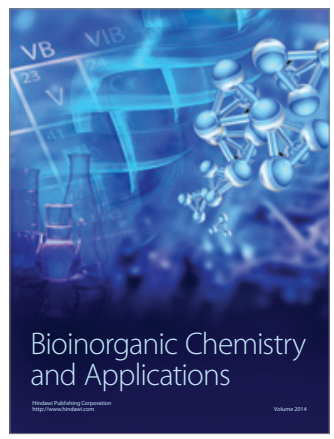

Inorganic Chemistry
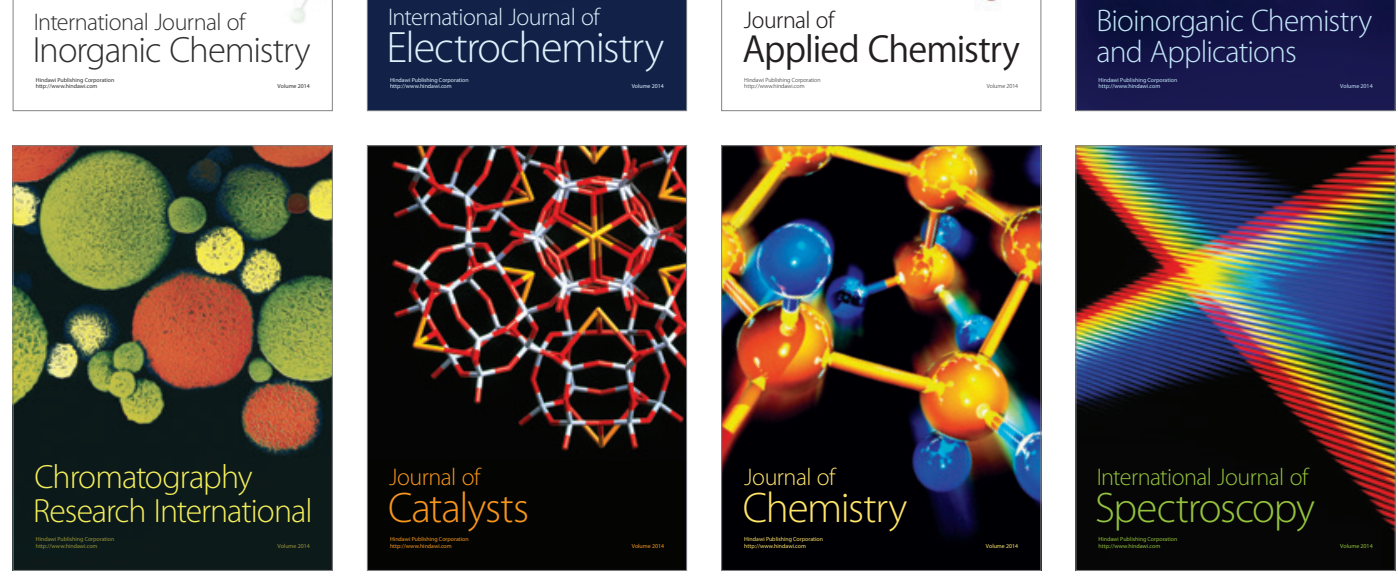